\title{
Clear evidence of electron delocalization: synthesis, structure, magnetism, EPR and DFT calculation of the asymmetric hexanickel string complex containing a single mixed-valence $\left(\mathrm{Ni}_{2}\right)^{3+}$ unit $\dagger+$
}

\author{
Isiah Po-Chun Liu, $\S^{a, b}$ Chi-Fen Chen, ${ }^{a}$ Shao-An Hua, ${ }^{a}$ Chi-Hui Chen, ${ }^{a}$ Hui-Ting Wang, ${ }^{a}$ Gene-Hsiang Lee ${ }^{a}$ and \\ Shie-Ming Peng*a,b
}

\author{
Received 26th January 2009, Accepted 12th February 2009 \\ First published as an Advance Article on the web 13th March 2009 \\ DOI: 10.1039/b901675a
}

This paper describes the physical properties of the $\left(\mathrm{Ni}_{2}\right)^{3+}$ mixed-valence unit that is an excellent conductivity-enhanced tool for metal string complexes.

Metal string complexes that contain a 1D linear transition metal backbone are considered to be potential molecular electronic devices. ${ }^{1}$ The general expectation is to transport an electron through the continua of metal wire-like frameworks that are similar to the electric wires in our macroscopic world. Thus, these metal string complexes could be essential units to the assembly of any type of nano-electronic devices. Because of this potentially useful property, a series of metal string complexes have been synthesized and studied in our group and others. ${ }^{2}$ In order to test the qualitative electron-transfer (ET) efficiency of tri- and penta-nuclear metal strings, the scanning tunneling microscopy $(\mathrm{STM})^{3}$ methodology had been carried out previously by Chen et $a{ }^{4}{ }^{4}$ The STM measurements show that the conductivity is dependent on the extent of electronic delocalization along the metal string. That is, the metal strings with stronger metalmetal interaction, ${ }^{5}$ exhibit better conductivity. ${ }^{4}$ Among these compounds, polynickel string complexes have the weakest metalmetal interaction and are less conductive than their cobalt and chromium analogues ${ }^{4}$, however, because of the easier synthetic method and high yield of polynickel string complexes, they are still among the most important materials in this field. In order to improve the conductivity of polynickel string complexes, we attempted to insert the mixed-valence $\left(\mathrm{Ni}_{2}\right)^{3+}$ unit into the linear pentanickel framework. ${ }^{6,7}$ The resulting mixed-valence pentanickel string complex, $\left[\mathrm{Ni}_{5}(\text { bna })_{4}(\mathrm{NCS})_{2}\right](\mathrm{NCS})_{2} \quad($ bna $=$ bisnaphthyridylamide), shows about $40 \%$ enhancement of the conductivity in comparison with that of typical $\left[\mathrm{Ni}_{5}\right]^{10+}$ complex, $\left[\mathrm{Ni}_{5}(\mathrm{tpda})_{4}(\mathrm{NCS})_{2}\right]($ tpda $=$ tripyridyldiamide $)$, which may be due

${ }^{a}$ Department of Chemistry, National Taiwan University, Taipei, 106, Taiwan (ROC).E-mail: smpeng@ntu.edu.tw; Fax: (+886)2-8369-3765

${ }^{b}$ Institute of Chemistry, Academia Sinica, Taipei, 115, Taiwan (ROC)

$\dagger$ Electronic supplementary information (ESI) available: Synthesis of $\mathrm{H}_{2}$ napany and 1; details of computational methods and X-ray structure determination. CCDC reference number 711829. For ESI and crystallographic data in CIF or other electronic format see DOI: 10.1039/b901675a $\$$ Crystal data for 1: $\mathrm{C}_{96} \mathrm{H}_{76} \mathrm{~B}_{2} \mathrm{Cl}_{15} \mathrm{~F}_{8} \mathrm{~N}_{24} \mathrm{Ni}_{6} \mathrm{O}_{2}, M_{\mathrm{w}}=2655.44$, triclinic, space group $P-1, a=12.7134(3) \AA, b=21.0171(5) \AA, c=22.4171(6) \AA$, $\alpha=67.7665(13)^{\circ}, \beta=74.9828(13)^{\circ}, \gamma=84.5772(12)^{\circ}, V=5355.1(2) \AA^{3}$, $Z=2, D_{\text {calcd }}=1.647 \mathrm{mg} \mathrm{m}^{-3}, T=150$ (2) K, 64688 reflection collected, 18813 independent, $R_{\text {int }}=0.1048, R_{l}=0.1874, w R_{2}=0.2676$ for all data. Moiety formula $=1 \cdot 0.5\left(\mathrm{C}_{2} \mathrm{H}_{8} \mathrm{O}_{2}\right) \cdot 7\left(\mathrm{CH}_{2} \mathrm{Cl}_{2}\right) \cdot \mathrm{H}_{2} \mathrm{O}$. The details were included in CIF files.

$\S$ Current address: Department of Chemistry, Purdue University, West Lafayette, IN 47907, USA. to the great electron mobility within the $\left(\mathrm{Ni}_{2}\right)^{3+} \cdot{ }^{7}$ Although the $\left(\mathrm{Ni}_{2}\right)^{3+}$ unit has been proven to be a practical tool to enhance conductivity, up to now, its physical properties remained unclear. The reason for this can be attributed to the fact that there are two $\left(\mathrm{Ni}_{2}\right)^{3+}$ units with a strong electronic coupling within the pentanickel framework. ${ }^{7}$ In our previous report, the mixedvalence $\left(\mathrm{Ni}_{2}\right)^{3+}$ unit was tentatively assigned as a Robin-Day class II compound (partly delocalized) ${ }^{7,8}$ However, because of the importance of the $\left(\mathrm{Ni}_{2}\right)^{3+}$ unit, its fundamental physical properties are still worth extensive study. In this work, we report the synthesis, X-ray structure, magnetic properties and DFT calculations of $\left.(4,0)\left[\mathrm{Ni}_{6} \text { (napany }\right)_{4} \mathrm{Cl}\right]\left(\mathrm{BF}_{4}\right)_{2}(\mathbf{1})$, that is supported by the anion of new asymmetric 2-(naphthyridylamino)-7-phenylamino-1,8naphthyridine ( $\mathrm{H}_{2}$ napany) ligand. Compound 1 contains only one mixed-valence $\left(\mathrm{Ni}_{2}\right)^{3+}$ unit, which directly shows its important physical properties.

The $\mathrm{H}_{2}$ napany ligand (Scheme 1) was prepared by the reaction of 2,7-dichloro-1,8-naphthyridine, ${ }^{9} \quad$ 2-amino-1,8-naphthyridine ${ }^{7}$ and aniline with a palladium catalyst. Treatment of $\mathrm{H}_{2}$ napany with $\mathrm{NiCl}_{2}$ in the presence of $t$-BuOK, followed by excess of $\mathrm{NaBF}_{4}$, generated compound $\mathbf{1}$. The crystal structure of $\mathbf{1}$ is shown in Fig. 1. The core structure of 1 reveals a $\left(\mathrm{Ni}_{6}\right)^{11+}$ core helically wrapped by four napany ${ }^{2-}$ ligands. The napany ${ }^{2-}$ ligands adopt a $(4,0)$ arrangement with all anilino $\mathrm{N}$ ions coordinated to the $\mathrm{Ni}(6)$ ion exhibiting approximated $C_{4}$ symmetry. ${ }^{17 a, 18 f}$ The $\mathrm{Ni}(1)$ ion is square pyramidal coordinated with a longer averaged $\mathrm{Ni}(1)-\mathrm{N}$ distance $(2.136 \AA$ ), which is consistent with a high spin ( $\mathrm{S}=1$ ) $\mathrm{Ni}(\mathrm{II})$ environment. ${ }^{9}$ The $\mathrm{Ni}(3), \mathrm{Ni}(4), \mathrm{Ni}(5)$ and $\mathrm{Ni}(6)$ ions, on the contrary, are low spin $(\mathrm{S}=0) \mathrm{Ni}$ ions because of their square planar geometries and shorter $\mathrm{Ni}-\mathrm{N}$ distances $(\sim 1.90 \AA) .{ }^{10}$ Based on our previous study, the Ni(2) ion can be assigned as a $\mathrm{Ni}(\mathrm{I})(\mathrm{S}=1 / 2)$ ion. ${ }^{7}$ The slightly longer $\mathrm{Ni}(2)-\mathrm{N}$ distance $(2.032 \AA)$ is due to the presence of one unpaired electron to be accommodated in molecular orbitals (MOs) with $\mathrm{Ni}-\mathrm{N}$ antibonding character. ${ }^{7}$ Compared with the general outermost

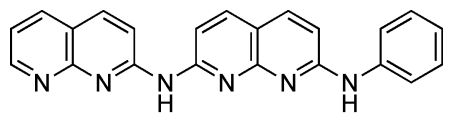

$\mathrm{H}_{2}$ napany

Scheme 1 


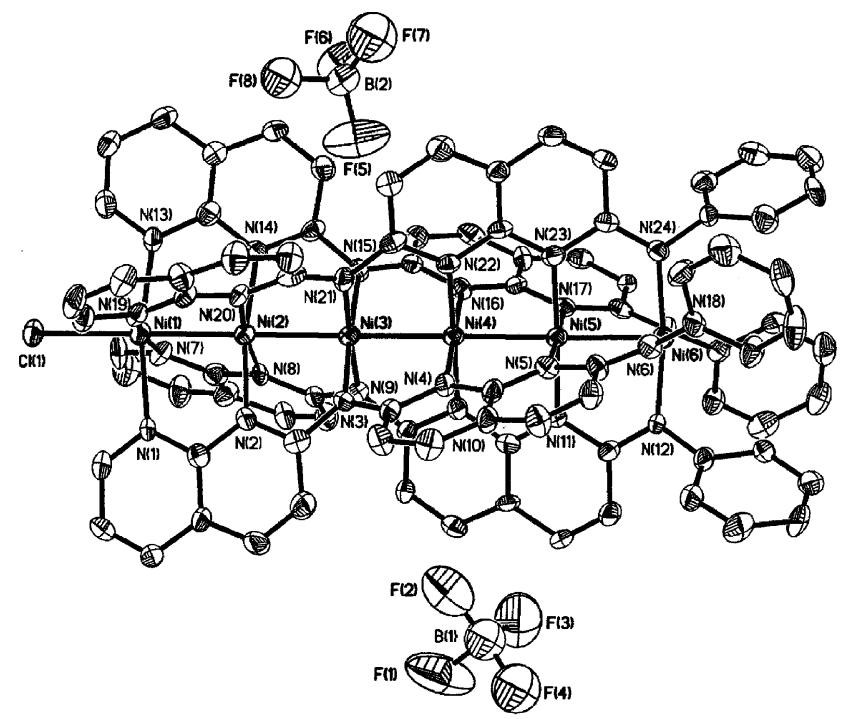

Fig. 1 ORTEP view of the molecular structure of the $\left.(4,0)\left[\mathrm{Ni}_{6} \text { (napany }\right)_{4} \mathrm{Cl}\right]\left(\mathrm{BF}_{4}\right)_{2}(\mathbf{1})(50 \%$ probability). Selected bond distances (averaged): $\mathrm{Ni}(1)-\mathrm{Cl}$ 2.388(2), $\mathrm{Ni}(1)-\mathrm{Ni}(2) \quad 2.3340(16), \quad \mathrm{Ni}(2)-\mathrm{Ni}(3)$ 2.3368(15), Ni(3)-Ni(4) 2.3165(15), Ni(4)-Ni(5) 2.3089(15), Ni(5)-Ni(6) 2.3525(15), Ni(1)-N 2.136(7), Ni(2)-N 2.032(7), Ni(3)-N 1.897(7), $\mathrm{Ni}(4)-\mathrm{N} 1.911(7), \mathrm{Ni}(5)-\mathrm{N} 1.903(7), \mathrm{Ni}(6)-\mathrm{N} 1.912(7) \AA$.

$\mathrm{Ni}-\mathrm{Ni}$ bond length $(\sim 2.40 \AA)$ of polynickel string compounds, ${ }^{9}$ the relatively short terminal $\mathrm{Ni}(1)-\mathrm{Ni}(2)$ distance $(2.33 \AA)$ of $\mathbf{1}$ results from the formation of a $\mathrm{Ni}(1)-\mathrm{Ni}(2) \sigma$-bond. ${ }^{7}$

The $\chi_{\mathrm{m}} T$ value $\left(\mathrm{cm}^{3} \mathrm{~K} \mathrm{~mol}{ }^{-1}\right)$ of 1 is $c a .1 .65$ at $300 \mathrm{~K}$ (Fig. 2), which is approaching the value for $\mathrm{S}=3 / 2$ ( $c$ a. 1.88). In general, a strong antiferromagnetic interaction of 1 between the unpaired electrons that occupy the $\mathrm{d}_{x^{2}-y^{2}}$ orbitals of $\mathrm{Ni}(1)$ and $\mathrm{Ni}(2)$ ions should be expected, which result from the throughspace delocalization of the spin density. ${ }^{11}$ This curve, however, is nearly constant, which indicates that the ground state of $\mathbf{1}$ is $\mathrm{S}=3 / 2$ with no contribution from the thermally-populated $\mathrm{S}=1 / 2$ state. The $\mathrm{S}=3 / 2$ ground state is considered to accompany the electron delocalization that arises from the so-called spindependent delocalization or double exchange mechanism. ${ }^{12}$ This term suggests that the ground state of the mixed-valence complexes

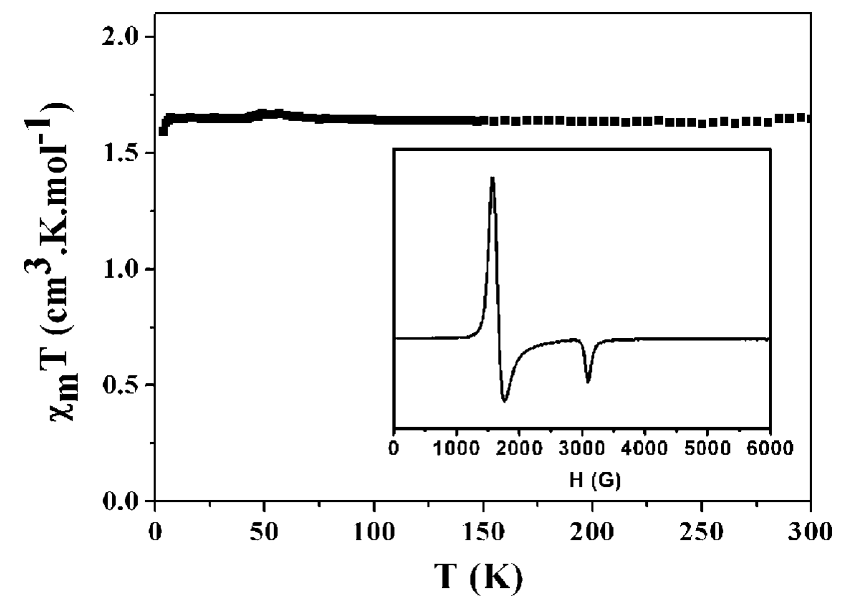

Fig. 2 Plot of $\chi_{\mathrm{m}} T(\square)$ versus $T$ of complex 1. Inset: powder X-band EPR spectrum of 1 at $4 \mathrm{~K}$. depends not only on the exchange coupling constant $J$ but also on the transfer integral $\beta$. When $|\beta / J|$ increases, the ground state strongly favors the highest spin-state and the transferable electron can move from one site to the other without a spin flip. ${ }^{12}$ The powder EPR spectrum of $\mathbf{1}$ at $4.2 \mathrm{~K}$ is shown in Fig. 2 (inset). It exhibits two resonances centered at $g_{\perp}=4.47$ and $g_{\|}=2.17$. This spectrum is a typical signal of an $\mathrm{S}=3 / 2$ ground state with large zero-field splitting, which corroborates the susceptibility measurement of $1 .{ }^{13}$ Based on the crystal structure of $\mathbf{1}$, the coordinated environments of $\mathrm{Ni}(1)$ and $\mathrm{Ni}(2)$ ions are not symmetrical, thus excluding 1 from Robin-Day class III compound classification (fully delocalized). The three unpaired electrons of the mixed-valence $\left(\mathrm{Ni}_{2}\right)^{3+}$ unit of $\mathbf{1}$ can be qualitatively assigned to be partly delocalized (class II), which is similar to that of our previous report. ${ }^{7,8,14}$ The class II compound $\mathbf{1}$ has, in principle, an intermediate behaviour which leads to a temperaturedependent delocalization. ${ }^{14}$ The magnetic susceptibility measurement and EPR spectrum in this study clearly show that to activate the delocalization of these three electrons, only minimal thermal energy is required $(\sim 4 \mathrm{~K})$. Compound $\mathbf{1}$ may therefore be assigned as a borderline class III compound.

The DFT/B3LYP calculations were carried out on 1 with the GAUSSIAN03 software package..$^{15}$ For the sake of simplicity, the phenyl ring of the ligand napany ${ }^{2-}$ is replaced by a methyl group. The geometry of 1 was optimized in the idealized $C_{4}$ symmetry in high-spin $(\mathrm{S}=3 / 2)$ and low-spin $(\mathrm{S}=1 / 2)$ states (Fig. 3, upper). Because the description of the low-spin state cannot be handled within conventional DFT, we approximate this state by performing the broken symmetry (BS) formalism. ${ }^{16}$ The computed bond distances of $\mathrm{S}=3 / 2$ state are in good agreement with the experimental data, especially the trend of $\mathrm{Ni}(1)-\mathrm{Ni}(2)$ and $\mathrm{Ni}(2)-\mathrm{Ni}(3)$ bond lengths. The computed geometry obtained from the BS state, however, gives elongated $\mathrm{Ni}(1)-\mathrm{Ni}(2)$ and contracted $\mathrm{Ni}(2)-\mathrm{Ni}(3)$ bond distances, which is similar to the typical feature of "electron-localized" polynickel string complexes. ${ }^{2,7,9,10}$ This calculation placed the $\mathrm{S}=3 / 2$ state $0.24 \mathrm{eV}\left(1970 \mathrm{~cm}^{-1}\right)$ below the $\mathrm{S}=1 / 2$ state, which supports the experimental $\mathrm{S}=3 / 2$ ground

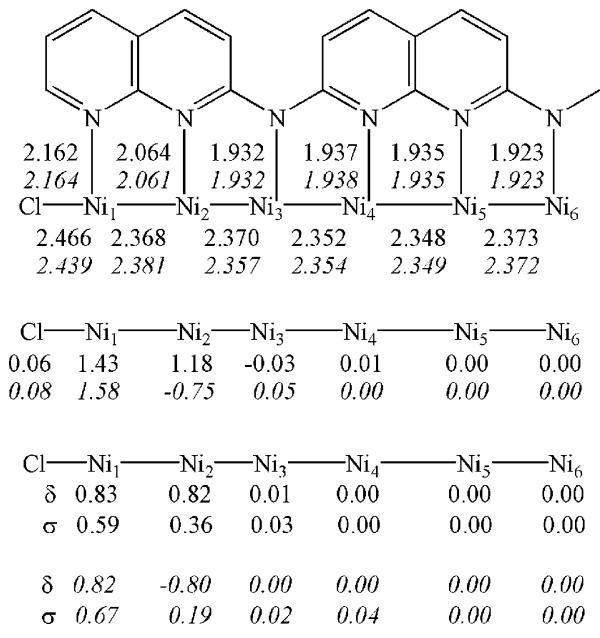

Fig. 3 Selected computed bond distances ( $\AA$, upper), atomic spin densities $(e$, middle) and gross atomic spin orbital population $(\alpha$ spin $-\beta$ spin, e; Mulliken analysis, bottom) for $\mathrm{S}=3 / 2$ and $\mathrm{S}=1 / 2$ (italics) states of $1 . \sigma$ represents the $\mathrm{d}_{z^{2}}$ spin population and $\delta$ indicates the $\mathrm{d}_{x y}+\mathrm{d}_{x^{2}-y^{2}}$ spin population. 
state. The atomic spin density of complex $\mathbf{1}$ in the $\mathrm{S}=3 / 2$ state is $1.43 \mathrm{e}$ on the terminal $\mathrm{Ni}(1)$ and $1.18 \mathrm{e}$ on the $\mathrm{Ni}(2)$ ions (Fig. 3, middle). This distribution is practically half way between a localized (2 e on $\mathrm{Ni}(1)$ and $1 \mathrm{e}$ on $\mathrm{Ni}(2))$ and a fully delocalized distribution (1.5 e on $\mathrm{Ni}(1)$ and $\mathrm{Ni}(2))$, which indicates that compound $\mathbf{1}$ can be tentatively classified as class II (partly delocalized). This result supports the experimental structural feature which shows an asymmetric $\left(\mathrm{Ni}_{2}\right)^{3+}$ geometry and suggests that the delocalization of the spin density is not complete. The gross spin density $\left(\alpha-\beta\right.$, e) associated with the $\mathrm{d}_{z^{2}}$ and $\mathrm{d}_{x^{2}-y^{2}}$ for compound 1 is shown in Fig. 3 (bottom). The closed shell $\sigma$-orbital of the $\mathrm{Ni}(2)$ ion in the $\mathrm{S}=3 / 2$ state possesses positive spin density ( 0.36$)$ that indicates partial delocalization occurs along the metal axis via a transfer of the $\beta$ spin electron density from $\mathrm{Ni}(2)$ to $\mathrm{Ni}(1){ }^{6,7}$ Compared with those in the $\mathrm{S}=3 / 2$ state, the gross spin population of the $\sigma$-orbital of the $\mathrm{Ni}(2)$ ion with $\mathrm{S}=1 / 2$ is just slightly positive (0.19). This result shows the inhibition of the electron delocalization and decomposition of the $\mathrm{Ni}-\mathrm{Ni} \sigma$-bond (longer computed $\mathrm{Ni}(1)-\mathrm{Ni}(2)$ bond distance) when unpaired electrons of $\mathrm{Ni}(1)$ and $\mathrm{Ni}(2)$ ions are antiferromagnetically coupled. That is, it demonstrates qualitatively that the stabilization of the $\mathrm{S}=3 / 2$ state is due to electron delocalization.

In summary, in order to study the fundamental physical properties of the $\left(\mathrm{Ni}_{2}\right)^{3+}$ mixed-valence unit (conductivity-enhanced tool), we have designed and synthesized $\left.(4,0)\left[\mathrm{Ni}_{6} \text { (napany }\right)_{4} \mathrm{Cl}\right]\left(\mathrm{BF}_{4}\right)_{2}(\mathbf{1})$. This compound contains a unique $\left(\mathrm{Ni}_{2}\right)^{3+}$ mixed-valence unit which can provide direct evidence for electron delocalization. The crystal structure, magnetic measurement and EPR spectrum suggest that the three unpaired electrons of the $\left(\mathrm{Ni}_{2}\right)^{3+}$ unit are partly delocalized between two $\mathrm{Ni}$ ions and the thermal energy to activate this delocalized process is very small. DFT calculation supports the experimental results and demonstrates that the stabilization of the $S=3 / 2$ state is due to electron delocalization. ${ }^{12}$ Besides the fundamental research above, we consider that compound $\mathbf{1}$ may have potential applications in molecular electronic devices. It should be noted that most of the research of metal string complexes has, up to now, focused mainly on symmetric molecules. ${ }^{2}$ In the previous reports by Ren et al., the introduction of an asymmetric prototype, $\mathrm{Ru}_{2}$ complex, enhances the transconductance of organic molecular wires and may be used for memory application. ${ }^{17}$ The extended asymmetric compound $\mathbf{1}$ that possesses a delocalized $\left(\mathrm{Ni}_{2}\right)^{3+}$ mixed-valence unit is a suitable candidate for building novel asymmetric inorganic molecular wires and can be expected to broaden the scope of molecular electronic devices. ${ }^{18}$

\section{Notes and references}

1 (a) Extended Linear Chain Compounds, Vols. 1-3, ed. J. S. Miller, Plenum, New York, 1982; (b) S. Roth, One-Dimensional Metals, VCH, New York, 1995.

2 (a) J. F. Berry, F. A. Cotton, P. Lei, T. Lu and C. A. Murillo, Inorg. Chem., 2003, 42, 3534; (b) L.-G. Zhu and S.-M. Peng, Wuji Huaxue Xuebao, 2002, 18, 117; (c) C.-Y. Yeh, C.-C. Wang, C.-h. Chen and S.-M. Peng, in Nano Redox Sites: Nano-Space Control and its
Applications, ed. T. Hirao, Springer, Berlin, 2006, Chapter 5, pp. 85 117; (d) J. K. Bera and K. R. Dunbar, Angew. Chem., Int. Ed., 2002, 41, 4453; (e) H. Ohtsu, S. Takaishi, K. Imamura, A. Ishii, K. Tanaka, M. Hasegawa and M. Yamashita, Eur. J. Inorg. Chem., 2007, 4425; (f) H. Arakawa, D. Kawakami, S. Takaishi, T. Kajiwara, H. Miyasaka, K.-i. Sugiura, M. Yamashita, H. Kishida and H. Okamoto, Bull. Chem. Soc. Jpn., 2007, 80, 189.

3 L. A. Bumm, J. J. Arnold, M. T. Cygan, T. D. Dunbar, T. P. Burgin, L. Jones II, D. L. Allara, J. M. Tour and P. S. Weiss, Science, 1996, 271, 1705 .

4 (a) S.-Y. Lin, I.-W. P. Chen, C.-h. Chen, M.-H. Hsieh, C.-Y. Yeh, T.-W. Lin, Y.-H. Chen and S.-M. Peng, J. Phys. Chem. B, 2004, 108, 959; (b) I.-W. P. Chen, M.-D. Fu, W.-H. Tseng, J.-H. Yu, S.-H. Wu, C.-J. Ku, C.-h. Chen and S.-M. Peng, Angew. Chem., Int. Ed., 2006, 45, 5814.

5 J. F. Berry, F. A. Cotton, L. M. Daniels, C. A. Murillo and X. Wang, Inorg. Chem., 2003, 42, 2418.

6 (a) D. Gatteschi, C. Mealli and L. Sacconi, J. Am. Chem. Soc., 1973, 95, 2736; (b) L. Sacconi, C. Mealli and D. Gatteschi, Inorg. Chem., 1974, 13, 1985; (c) A. Bencini, D. Gatteschi and L. Sacconi, Inorg. Chem., 1978, 17, 2760; (d) A. Bencini, E. Berti, A. Caneschi, D. Gatteschi, E. Giannasi and I. Invernizzi, Chem.-Eur. J., 2002, 8, 3660.

7 I. P.-C. Liu, M. Bénard, H. Hasanov, I.-W. P. Chen, W.-H. Tseng, M.-D. Fu, M.-M. Rohmer, C.-h. Chen, G.-H. Lee and S.-M. Peng, Chem.Eur. J., 2007, 13, 8667.

8 (a) M. B. Robin and P. Day, Adv. Inorg. Chem. Radiochem., 1967, 10, 247; (b) S. F. Nelsen, Chem.-Eur. J., 2000, 6, 581 and references therein.

9 (a) C.-H. Chien, J.-C. Chang, C.-Y. Yeh, L.-M. Fang, Y. Song and S.-M. Peng, Dalton Trans., 2006, 3249; (b) C.-H. Chien, J.-C. Chang, C.-Y. Yeh, G.-H. Lee, L.-M. Fang and S.-M. Peng, Dalton Trans., 2006, 2106.

10 (a) J. F. Berry, F. A. Cotton, P. Lei, T. Lu and C. A. Murillo, Inorg. Chem., 2003, 42, 3534; (b) C.-C. Wang, W.-C. Lo, C.-C. Chou, G.-H. Lee, J.-M. Chen and S.-M. Peng, Inorg. Chem., 1998, 37, 4059; (c) J. F. Berry, F. A. Cotton, T. Lu, C. A. Murillo and X. Wang, Inorg. Chem., 2003, 42, 3595; (d) S.-Y. Lai, T.-W. Lin, Y.-H. Chen, C.-C. Wang, G.-H. Lee, M.-h. Yang, M.-k. Leung and S.-M. Peng, J. Am. Chem. Soc., 1999, 121, 250; (e) M.-Y. Huang, C.-Y. Yeh, G.-H. Lee and Shie-Ming Peng, Dalton Trans., 2006, 5683.

11 (a) L. Gutiérrez, G. Alzuet, J. Borrás, A. Castiñeiras, A. RodríguezFortea and E. Ruiz, Inorg. Chem., 2001, 40, 3089; (b) I. P.-C. Liu, G.-H. Lee, S.-M. Peng, M. Bénard and M.-M. Rohmer, Inorg. Chem., 2007, 46, 9602.

12 (a) C. Zener, Phys. Rev., 1951, 82, 403; (b) P. W. Anderson and H. Hasegawa, Phys. Rev., 1955, 100, 675; (c) G. Blondin and J.-J. Girerd, Chem. Rev., 1990, 90, 1359.

13 R. S. Drago, Physical Methods for Chemists, 2nd edition, Saunders College Publishing, New York, 1992, Chapter 13.

14 Mixed Valence Compounds, ed. D. M. Brown, D. Reidel, Dordrecht, Holland, 1980.

15 M. J. Frisch, et al. GAUSSIAN03, Revision B.05Gaussian, Inc.: Pittsburgh, PA, 2003.

16 (a) A. P. Ginsberg, J. Am. Chem. Soc., 1980, 102,111; (b) L. Noodleman, J. Chem. Phys., 1981, 74, 5737; (c) L. Noodleman and E. J. Baerends, J. Am. Chem. Soc., 1984, 106, 2316; (d) L. Noodleman and E. R. Davidson, Chem. Phys., 1986, 109, 131; (e) L. Noodleman, J. G. Norman, J. H. Osborne, A. Aizman and D. A. Case, J. Am. Chem. Soc., 1985, 107, 3418; $(f)$ L. Noodleman, D. A. Case and A. Aizman, J. Am. Chem. Soc., 1988, 110, 1001; (g) L. Noodleman, C. Y. Peng, D. A. Case and J. M. Mouesca, Coord. Chem. Rev., 1995, 144, 199.

17 (a) A. S. Blum, T. Ren, D. A. Parish, S. A. Trammell, M. H. Moore, J. G. Kushmerick, G.-L. Xu, J. R. Deschamps, S. K. Pollack and R. Shashidhar, J. Am. Chem. Soc., 2005, 127, 10010.

18 (a) M. H. Chisholm and N. J. Patmore, Acc. Chem. Res., 2007, 40, 19; (b) M. D. Ward, Chem. Soc. Rev., 1995, 34, 121; (c) D. Astruc, Acc. Chem. Res., 1997, 30, 383; (d) J. A. McCleverty and M. D. Ward, Acc. Chem. Res., 1998, 31, 842; (e) G. Zou, J. C. Alvarez and T. Ren, J. Organomet. Chem., 2000, 596, 152; (f) I. P.-C. Liu, C.-H. Chen, C.-F. Chen, G.-H. Lee and S.-M. Peng, Chem. Commun., 2009, 577. 